\title{
Selecting chemicals for separation of ABS and HIPS in WEEE by froth flotation
}

\author{
Solange Kazue Utimura ${ }^{1 *}$ (D), Arthur Pinto Chaves ${ }^{2}$, Jorge Alberto Soares Tenório ${ }^{1}$ and \\ Denise Crocce Romano Espinosa ${ }^{1}$
}

\begin{abstract}
'Laboratório de Reciclagem, Tratamento de Resíduos e Metalurgia Extrativa - LAREX, Departamento de Engenharia Química - PQI, Escola Politécnica, Universidade de São Paulo - USP, São Paulo, SP, Brasil ${ }^{2}$ Laboratório de Tratamento de Minérios e Resíduos Industriais - LTM, Departamento de Engenharia de Minas e de Petróleo - PMI, Escola Politécnica, Universidade de São Paulo - USP, São Paulo, SP, Brasil
\end{abstract}

*solange.utimura@usp.br

\begin{abstract}
The feasibility of using common chemicals to separate plastics from waste electrical and electronic equipment (WEEE) by froth flotation is investigated. Plastic waste is one of the WEEE polluters and a separation is necessary to recycle it. The most common plastics in electronic industries are acrylonitrile-butadiene-styrene (ABS) and high impact polystyrene (HIPS). These plastics are difficult to separate due to the similar specific weights and to both being repellent to water. Froth flotation allows for separating particles by the differences in their surface characteristics by selective wetting agents. The common chemicals are ethanol and acetic acid to depress the plastics. The process with $20 \%$ weight of ethanol was able to produce a recovery concentrate of HIPS with $98 \%$ and ABS with $96 \%$. The process with $40 \%$ weight of acetic acid produces a recovery concentrate of HIPS with $96 \%$ and ABS with $83 \%$.
\end{abstract}

Keywords: WEEE, froth flotation, plastics separation, plastics recovery.

How to cite: Utimura, S. K., Chaves, A. P., Tenório, J. A. S., \& Espinosa, D. C. R. (2019). Selecting chemicals for separation of ABS and HIPS in WEEE by froth flotation. Polímeros: Ciência e Tecnologia, 29(2), e2019017. https:// doi.org/10.1590/0104-1428.05718

\section{Introduction}

Brazil is the second major producer of electronic waste (e-waste) in the Americas, with $1.5 \mathrm{Mt}$ per year, which is around $7.1 \mathrm{~kg} / \mathrm{inh}$; yet only $13 \%$ of e-waste is treated appropriately. The global amount of e-waste generation in 2016 was arounf $44.7 \mathrm{Mt}$ and the amount of e-waste is expected to grow to $52.2 \mathrm{Mt}$ in $2021^{[1]}$.

E-waste is referred to as WEEE, electrical and electronic scrap from a wide range of products (computers, cell phones, laptops, TVs) with different components (batteries, LCD-TVs, lamps, printed circuit boards). WEEE involves valuable materials, including metals, plastics and glass. The opportunities for dismantling these materials make them an interesting business with a potential for reuse and recycling ${ }^{[2]}$.

WEEE demands specific equipment to dismantle, shred, process and extract the materials. These materials, such as plastics components, can be recycled for producing a new products. The advantages of recycling WEEE are conserving natural resources, preserving landfill space, reducing pollution and saving energy ${ }^{[3]}$.

The selective separation of plastic waste is an important step because these types of plastics should not be put together in the recycling operation reprocess. Contamination with other polymers with different melting points can limit the quality of plastic waste and cause some complications in physical properties, such as polymer-polymer incompatibility, discoloration and degradation products ${ }^{[4]}$.

A major difficulty in separating mixed plastics, is the natural hydrophobicity that is a feature of most plastics. Plastics have a floating property, caused by their non-wetting characteristic, and the selective wetting of one element is necessary for the separation process ${ }^{[5]}$. Different studies on plastic waste separation have used different methods and an efficient alternative is a mineral processing technique denominated froth flotation. The application of the flotation technique to plastic separation correlates properties, such as low surface energy and low density ${ }^{[6]}$.

Froth flotation was established for ore separation ${ }^{[7]}$. To apply this technique to plastic separation an appropriate chemical has to be added to selectively change the surface properties. The challenges in plastics flotation consist in selectively changing the surface characteristics from hydrophobic to hydrophilic properties ${ }^{[8]}$.

Many studies demonstrated that froth flotation technique has advantages in sorting mixture plastics. For example, Thanh Truc et al..$^{[9]}$ revealed the combination of $\mathrm{ZnO}$ and microwave treatment for the selective separation of ABS and HIPS from WEEE by froth flotation. Recently, Guo et al. ${ }^{[3]}$ separated ABS and PS from WEEE when using sodium hypochlorite as an aid of froth flotation. 
The purpose of this study was to separate the most common plastics content in WEEE as ABS and HIPS by the froth flotation and using attractive and common chemicals such as ethanol and acetic acid to make the plastic recycling process viable.

\section{Materials and Methods}

\subsection{Plastic waste preparation}

WEEE was collected from a recycling unit in a WEEE re-use center at the Universidade de São Paulo (USP - Brazil). The process starts by dismantling and separating the cables, plastics, metals and glass. The procedure used to identify the plastic was based on the resin identification code (RIC) of the Society of the Plastic Industry. The plastics used for the experiments were of different colors to visually analyze the concentrate samples manually at the end of their respective tests. The ABS and HIPS were shredded by a knife shredder (RONE FA2305) and separated into size fractions: 5.66; $2.83 ; 2.00 ; 1.00 ; 0.50$ and $0.30 \mathrm{~mm}$.

\subsection{Froth flotation experiment}

The samples used for froth flotation consisted of a mixture of $10 \mathrm{~g}$ of each plastic (ABS and HIPS) of the same sieve size. The reagent was used as a solution of ethanol P.A. ( $99.5 \%$ purity by CAAL) at different concentrations as well as the solution of acetic acid P.A. (99.7\% purity by CAAL).

The flotation tests were conducted in a glass column of $1,050 \mathrm{~mm}$ in height and $80 \mathrm{~mm}$ in diameter with a volumetric capacity of $3 \mathrm{dm}^{3}$. The bottom of the flotation column was fitted with a ceramic sparger plate (10-16- $\mu \mathrm{m}$ pore diameter) that was used to produce gas bubbles with compressed air $\left(3.0 \mathrm{dm}^{3} / \mathrm{min}\right)$. The sample was fed on top of the column that was a mixture of flotation fluid and gas. The hydrophilic particles were removed from the bottom (depressed plastics) and hydrophobic particles overflowed the flotation column ${ }^{[3]}$.

No additional frother was required and a 5-minute conditioning time was used. The floated plastics were mechanically removed after 10-minute flotation period. The floating and depressed plastics were collected respectively and dried under $50^{\circ} \mathrm{C}$ to calculate depressing and floating rates.

\section{Results and Discussions}

The work was started by running flotation experiments on shredded WEEE plastics with a suitable range of particle size between 2.00 and $2.83 \mathrm{~mm}$.

The appropriate range of plastic size can be 2.00 and $6.00 \mathrm{~mm}$ and influences on the floatability in selective separation of plastics. The plastic particles larger than $6 \mathrm{~mm}$ are more difficulty to float due the average of the specific gravity from the bubble-particle aggregate that is lower than the specific weight of the flotation medium. The particle size smaller than $1 \mathrm{~mm}$ increases the specific surface area and decreases the selectivity. The efficiency of the plastics separation depends on the plastics mixture type, the different hydrophobity grade, the size, density, shape of the particle and the particle weight ${ }^{[3,10]}$.

\subsection{Flotation with an aqueous ethanol solution}

The flotation reagent used for the tests consists of an ethanol aqueous solutions at different concentrations to control the surface tension. Selective wetting can be obtained by decreasing the surface tension of the flotation reagent in values whereby one plastic remains hydrophobic while another plastic changes into hydrophilic surface ${ }^{[11]}$. Figures 1 and 2 show the flotation experiments in aqueous ethanol solution at different concentrations with particle size between 2.00 to $2.83 \mathrm{~mm}$. The flotation "recovery" refers to the amount of plastic that could be separated in percentage of mass. The curves were obtained in duplicate and the results were reproducible.

The mixture of ABS and HIPS in flotation experiments consists in $10 \mathrm{~g}$ of each plastic type of the same sieve size. Figure 1 shows the aqueous solution of ethanol at $20 \%$ wt. The recovery of ABS was $96 \%$ or collected $9.6 \mathrm{~g}$ of ABS that depressed in the column. The ABS purity was $98 \%$ with ethanol at $20 \%$ wt., or of the total depressed plastic, $98 \%$ was ABS. Figure 2 shows that at $20 \%$ wt. ethanol concentration, the recovery of HIPS was $98 \%$ or $9.8 \mathrm{~g}$ of floated HIPS. The HIPS purity was $96 \%$ with ethanol concentration at $20 \% \mathrm{wt}$., or of the total float plastic, $96 \%$ was HIPS. No additional frother was required because ethanol increased the formation of small air bubbles and improved the flotation of particles. The formation

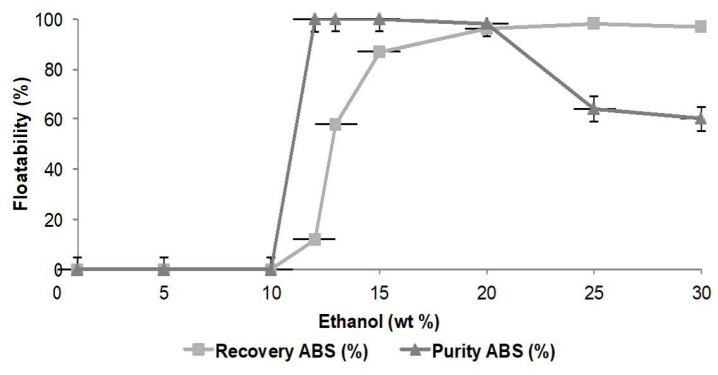

Figure 1. Flotation recovery and purity of $\mathrm{ABS}$ as a function of ethanol concentration. Error bars show $+/$ - standard deviation.

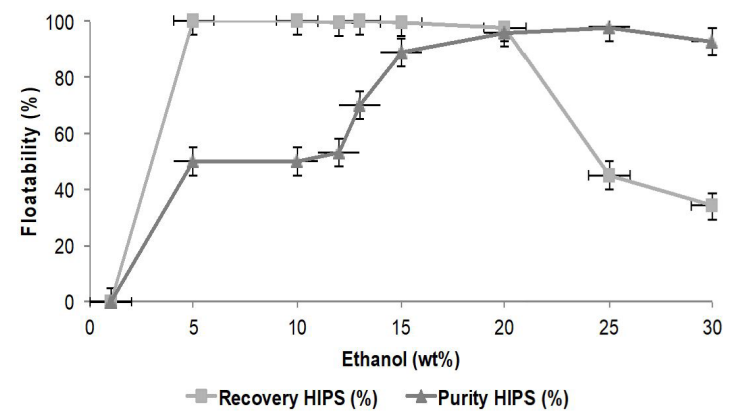

Figure 2. Flotation recovery and purity of HIPS as a function of ethanol concentration. Error bars show $+/$ - standard deviation. 
of the froth layer on the surface pulp happens when the air bubbles occur through the pulp due the portion of chemical molecules ${ }^{[12]}$.

\subsection{Flotation with an aqueous acetic acid solution}

Figure 3 and 4 show the flotation experiments according the aqueous solution of acetic acid at different concentrations with particle size between 2.00 and $2.83 \mathrm{~mm}$. The "recovery" refers to the amount of plastic that could be separated in percentage of mass. The curves were obtained in duplicate and the results were reproducible.

The ABS/HIPS samples used for the froth flotation tests, which consisted of $10 \mathrm{~g}$ of each plastic type of the same sieve size. Figure 3 shows the aqueous solution of acetic acid at $40 \%$ wt. The recovery of ABS was $83 \%$ or collected $8.3 \mathrm{~g}$ of ABS that depressed in the column. The ABS purity was $96 \%$ with acetic acid at $40 \%$ wt., or of the total depressed plastic, $96 \%$ was ABS. Figure 4 shows that at $40 \%$ of acetic acid concentration, the recovery of HIPS was $96 \%$ or $9.6 \mathrm{~g}$ of HIPS floated. The HIPS purity was $86 \%$ with $40 \%$ of acetic acid concentration ( $40 \%$ wt.) or of the total float plastic, $86 \%$ was HIPS.

Therefore, the flotation range used in these experiments was based on selectivity and achieved by reducing the surface tension of the liquid with ethanol and acetic acid aqueous solutions. The concentrations of ethanol and acetic acid control the surface tension of the flotation medium. The aqueous solutions of ethanol at $20 \%$ wt. and $40 \%$ wt. acetic acid were used to allow the separation of the ABS that depressed and the HIPS that floated.

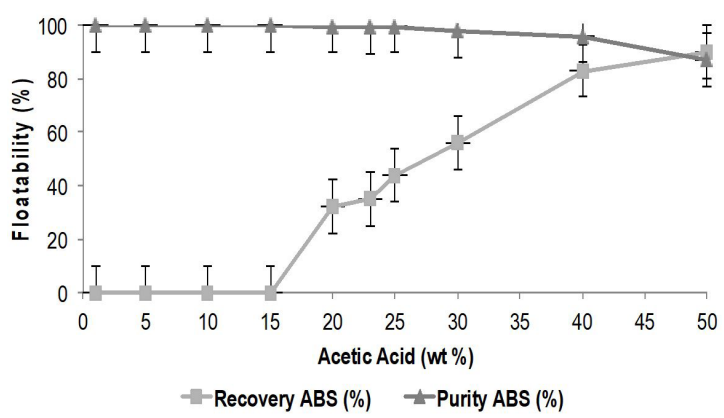

Figure 3. Flotation recovery and purity of ABS as a function of acetic acid concentration. Error bars show $+/$ - standard deviation.

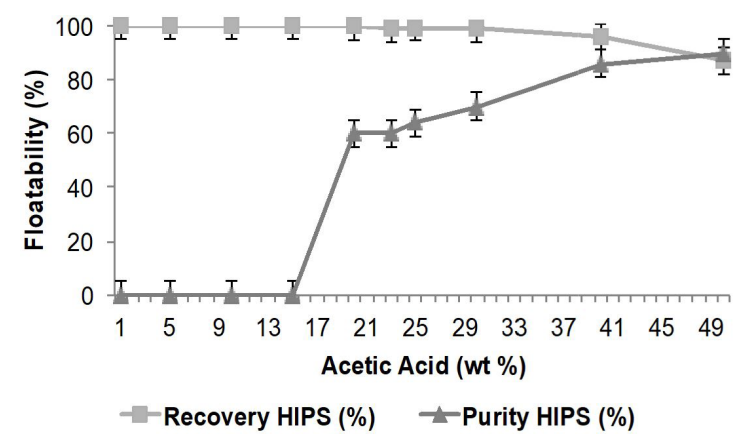

Figure 4. Flotation recovery and purity of HIPS as a function of acetic acid concentration. Error bars show $+/$ - standard deviation.

\section{Conclusions}

Froth flotation is a mineral process technique in which hydrophobic particles are selectively separated from the froth. The hydrophobic particles float and are separated from the hydrophilic particles, which are depressed into the solution. In this froth flotation process, it is possible to separate ABS and HIPS from WEEE. The separation of ABS and HIPS is reached by the use of surface tension control and by adjusting the experimental conditions that induce the selective flotation.

The experimental work used ethanol and acetic acid to depress plastics and yielded good results. The concentration of ethanol and acetic acid control the surface tension and the aqueous solutions of ethanol at $20 \%$ wt. concentration and $40 \%$ wt. acetic acid were found to allow the separation of the ABS that depressed and the HIPS that floated.

\section{Acknowledgments}

The authors are grateful for the financial support provided by CNPq (The Brazilian National Council for Scientific and Technological Development) and Fapesp (The State of São Paulo Research Foundation), Thematic Project 2012/51871-9 for this work.

\section{References}

1. Baldé, C. P., Forti, V., Gray, V., Kuehr, R., \& Stegmann, P. (2017). The global E-waste monitor 2017: quantities, flows, and resources. Vienna: UNU, ITU, ISWA.

2. Suresh, S. S., Bonda, S., Mohanty, S., \& Nayak, S. K. (2018). A review on computer waste with its special insight to toxic elements, segregation and recycling techniques. Process Safety and Environmental Protection, 116, 477-493. http://dx.doi. org/10.1016/j.psep.2018.03.003.

3. Guo, C., Zou, Q., Wang, J., Wang, H., Chen, S., \& Zhong, Y. (2018). Application of surface modification using sodium hypochlorite for helping flotation separation of acrylonitrilebutadiene-styrene and polystyrene plastics of WEEE. Waste Management (New York, N.Y.), 82, 167-176. http://dx.doi. org/10.1016/j.wasman.2018.10.031. PMid:30509579.

4. Wang, H., Wang, J., Zou, Q., Liu, W., Wang, C., \& Huang, W. (2018). Surface treatment using potassium ferrate for separation of polycarbonate and polystyrene waste plastics by froth flotation. Applied Surface, 448, 219-229. http://dx.doi. org/10.1016/j.apsusc.2018.04.091.

5. Negari, M. S., Ostad Movahed, S., \& Ahmadpour, A. (2018). Separation of polyvinylchloride (PVC), polystyrene (PS) and polyethylene terephthalate (PET) granules using various chemical agentes by flotation technique. Separation and Publication Technology, 194, 368-376. http://dx.doi.org/10.1016/j. seppur.2017.11.062.

6. Thakur, S., Verma, A., Sharma, B., Chaudhary, J., Tamulevicius, S., \& Thakur, V. K. (2018). Recent developments in recycling of polystyrene based plastics. Green and Sustainable Chemistry, 13, 32-38. http://dx.doi.org/10.1016/j.cogsc.2018.03.011.

7. Braga, P. F. A., Chaves, A. P., Luz, A. B., \& França, S. C. A. (2014). The use of dextrin in purification by flotation of molybdenite concentrates. International Journal of Mineral Processing, 127, 23-27. http://dx.doi.org/10.1016/j.minpro.2013.12.007.

8. Wang, J., Wang, H., Wang, C., Zhang, L., Wang, T., \& Zheng, L. (2017). A novel process for separation of hazardous poly(vinyl chloride) from mixed plastic wastes by froth flotation. Waste 
Management (New York, N.Y.), 69, 59-65. http://dx.doi. org/10.1016/j.wasman.2017.07.049. PMid:28801216.

9. Thanh Truc, N. T., \& Lee, B.-K. (2017). Selective separation of ABS/PC containing BFRs from ABSs mixture of WEEE by developing hydrophilicity with $\mathrm{ZnO}$ coating under microwave treatment. Journal of Hazardous Materials, 329, 84-91. http:// dx.doi.org/10.1016/j.jhazmat.2017.01.027. PMid:28126573.

10. Pita, F., \& Castilho, A. (2017). Separation of plastics by froth flotation. The role of size, shape and density of the particles. Waste Management (New York, N.Y.), 60, 91-99. http://dx.doi. org/10.1016/j.wasman.2016.07.041. PMid:27478025.

11. Chen, S., Zhang, Y., Guo, C., Zhong, Y., Wang, K., \& Wang, H. (2019). Separation of polyvinyl chloride from waste plastic mixture by froth flotation after surface modification with sodium persulfate. Journal of Cleaner Production, 218, 167-172. http://dx.doi.org/10.1016/j. jclepro.2019.01.280.

12. Truc, N. T. T., \& Lee, B. K. (2017). Combining ZnO/microwave treatment for changing wettability of WEEE styrene plastics (ABS and HIPS) and their selective separation by froth flotation. Applied Surface, 420, 746-752. http://dx.doi.org/10.1016/j. apsusc.2017.04.075.
Received: Dec. 03, 2018

Revised: Feb. 28, 2019

Accepted: Mar. 01, 2019 